University of New Hampshire

University of New Hampshire Scholars' Repository

Physics Scholarship

Physics

$12-20-2010$

\title{
Metastable anions of dinitrobenzene: resonances for electron attachment and kinetic energy release
}
A. Mauracher
S. Denifl
A. Edtbauer
M. Hager
M. Probst

See next page for additional authors

Follow this and additional works at: https://scholars.unh.edu/physics_facpub

Part of the Physics Commons

\section{Recommended Citation}

The following article appeared in J. Chem. Phys. 133, 244302 (2010); doi: 10.1063/1.3514931 and may be found at http://dx.doi.org/10.1063/1.3514931.

This Article is brought to you for free and open access by the Physics at University of New Hampshire Scholars' Repository. It has been accepted for inclusion in Physics Scholarship by an authorized administrator of University of New Hampshire Scholars' Repository. For more information, please contact Scholarly.Communication@unh.edu. 


\section{Authors}

A. Mauracher, S. Denifl, A. Edtbauer, M. Hager, M. Probst, Olof E. Echt, T. D. Maerk, P. Scheier, T. A. Field, and K. Graupner 


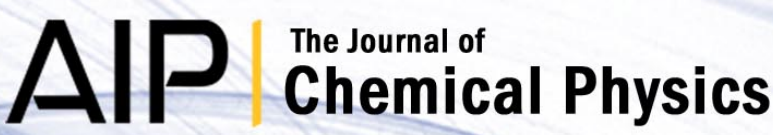

Metastable anions of dinitrobenzene: Resonances for electron attachment and kinetic energy release

A. Mauracher, S. Denifl, A. Edtbauer, M. Hager, M. Probst et al.

Citation: J. Chem. Phys. 133, 244302 (2010); doi: 10.1063/1.3514931

View online: http://dx.doi.org/10.1063/1.3514931

View Table of Contents: http://jcp.aip.org/resource/1/JCPSA6/v133/i24

Published by the American Institute of Physics.

Additional information on J. Chem. Phys.

Journal Homepage: http://jcp.aip.org/

Journal Information: http://jcp.aip.org/about/about_the_journal

Top downloads: http://jcp.aip.org/features/most_downloaded

Information for Authors: http://jcp.aip.org/authors

\section{ADVERTISEMENT}
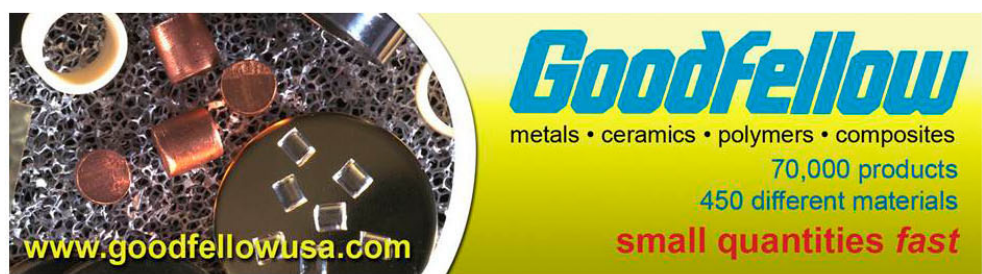


\title{
Metastable anions of dinitrobenzene: Resonances for electron attachment and kinetic energy release
}

\author{
A. Mauracher, ${ }^{1, \text { a) }}$ S. Denifl, ${ }^{1}$ A. Edtbauer,${ }^{1}$ M. Hager, ${ }^{1}$ M. Probst,${ }^{1}$ O. Echt, ${ }^{1,2, b)}$ \\ T. D. Märk, ${ }^{1,3}$ P. Scheier, ${ }^{1, c)}$ T. A. Field, ${ }^{4}$ and K. Graupner ${ }^{4}$ \\ ${ }^{1}$ Institut für Ionenphysik und Angewandte Physik and Center for Molecular Biosciences Innsbruck, \\ Leopold Franzens Universität, 6020 Innsbruck, Austria \\ ${ }^{2}$ Department of Physics, University of New Hampshire, Durham, New Hampshire 03820, USA \\ ${ }^{3}$ Department of Experimental Physics, Comenius University Bratislava, 84248 Bratislava, Slovakia \\ ${ }^{4}$ Center for Plasma Physics, Department of Physics and Astronomy, Queen's University Belfast, Belfast BT7 \\ INN, United Kingdom
}

(Received 19 July 2010; accepted 21 October 2010; published online 22 December 2010)

\begin{abstract}
Attachment of free, low-energy electrons to dinitrobenzene (DNB) in the gas phase leads to $\mathrm{DNB}^{-}$ as well as several fragment anions. $\mathrm{DNB}^{-},(\mathrm{DNB}-\mathrm{H})^{-},(\mathrm{DNB}-\mathrm{NO})^{-},(\mathrm{DNB}-2 \mathrm{NO})^{-}$, and $(\mathrm{DNB}-$ $\left.\mathrm{NO}_{2}\right)^{-}$are found to undergo metastable (unimolecular) dissociation. A rich pattern of resonances in the yield of these metastable reactions versus electron energy is observed; some resonances are highly isomer-specific. Most metastable reactions are accompanied by large average kinetic energy releases (KER) that range from 0.5 to $1.32 \mathrm{eV}$, typical of complex rearrangement reactions, but $(1,3-$ DNB-H $)^{-}$features a resonance with a KER of only $0.06 \mathrm{eV}$ for loss of NO. (1,3-DNB-NO) ${ }^{-}$offers a rare example of a sequential metastable reaction, namely, loss of $\mathrm{NO}$ followed by loss of $\mathrm{CO}$ to yield $\mathrm{C}_{5} \mathrm{H}_{4} \mathrm{O}^{-}$with a large KER of $1.32 \mathrm{eV}$. The G4(MP2) method is applied to compute adiabatic electron affinities and reaction energies for several of the observed metastable channels. (C) 2010 American Institute of Physics. [doi:10.1063/1.3514931]
\end{abstract}

\section{INTRODUCTION}

Concerns about public security have spurred renewed interest in the properties and identification of nitroaromatic compounds. Airport security and landmine detection call for selective, rapid detection of explosives with high sensitivity and low false alarm rate. Gas-phase detection of 2,4,6trinitrotoluene (TNT), an explosive commonly used in landmines, is hampered by its low vapor pressure. However, slow degradation of TNT results in trinitrobenzene, dinitrobenzene, and dinitrotoluene which feature much higher vapor pressures and are thus more amenable to detection in the gas phase. ${ }^{1}$

Negative ion mass spectra tend to be more informative than positive ion mass spectra because the amount of excess energy deposited in a parent anion is well defined if free electrons are attached to neutrals in the gas phase. ${ }^{2}$ Furthermore, low-energy electron attachment often leads to enhanced metastable ion dissociation which may help in the identification of the neutrals.

Anions of dinitrobenzene $\left(\mathrm{C}_{6} \mathrm{H}_{4} \mathrm{~N}_{2} \mathrm{O}_{4}\right.$, DNB) have also received attention because of their role in electron-transfer reactions in electrochemical reactions. ${ }^{3}$ Strong charge localization on one of the $\mathrm{NO}_{2}$ groups gives rise to an asymmetric ground state for isolated 1,3-DNB anions, about $0.17 \mathrm{eV}$ below the $\mathrm{C}_{2 \mathrm{v}}$ symmetric anion state. ${ }^{4}$ Adiabatic electron affinities (AEA) of the three isomers of DNB have been determined

\footnotetext{
a) Present address: Institutionen för materialkemi, Ångström Laboratoriet, Uppsala Universitet, 75121 Uppsala, Sweden.

b)Electronic mail: olof.echt@unh.edu.

c) Electronic mail: Paul.Scheier@uibk.ac.at.
}

from the temperature dependence of equilibrium constants for gas-phase electron transfer reactions. ${ }^{5-7}$ The values are modest, $1.65 \mathrm{eV}$ for 1,2-DNB and 1,3-DNB, and $2.00 \mathrm{eV}$ for 1,4DNB. ${ }^{6-8}$ Some of the fragments of DNB anions feature larger electron affinities which, combined with the low thermochemical stability of neutral DNB, implies that attachment of lowenergy electrons to DNB may trigger dissociative reactions that are accompanied by large kinetic energy release (KER), similar to a recently described highly exothermic reaction for electron attachment to 2,4-dinitrotoluene. ${ }^{9}$ Interestingly, these reactions may occur in the metastable time window, i.e., microseconds after electron attachment. Bowie et al. ${ }^{10}$ have reported kinetic energy release values of $0.5-1.0 \mathrm{eV}$ for the metastable reaction

$$
\mathrm{DNB}+\mathrm{e} \rightarrow \mathrm{DNB}^{*-} \rightarrow(\mathrm{DNB}-\mathrm{NO})^{-}+\mathrm{NO}
$$

for all three isomers of DNB. However, the authors did not measure the dependence of reaction 1 on the electron energy because they used secondary electrons whose energy could not be varied in a controlled way. Further, their report did not mention metastable reactions of DNB fragment anions.

In a recent publication we have presented anion mass spectra of 1,2-DNB ( $o$-DNB), 1,3-DNB ( $m$-DNB), and $1,4-\mathrm{DNB}(p$-DNB), and their dependence on the electron energy. ${ }^{11}$ Several anions were observed, each with a characteristic, isomer-specific energy dependence, including $\mathrm{DNB}^{-}$, $(\mathrm{DNB}-\mathrm{H})^{-},(\mathrm{DNB}-\mathrm{NO})^{-},\left(\mathrm{DNB}^{-\mathrm{NO}_{2}}\right)^{-},(\mathrm{DNB}-2 \mathrm{NO})^{-}$, and (DNB-2NO-CO $)^{-}$; some of these ions result from complex reactions associated with multiple bond cleavages and structural and electronic rearrangement. ${ }^{11}$ In the present work we investigate metastable dissociation of these anions. Two 
different experimental setups are used in our collaborative study: the Belfast apparatus includes a linear time-of-flight (TOF) mass spectrometer with a two-zone extraction region and a pulsed trochoidal electron monochromator; the Innsbruck apparatus consists of a double focusing mass spectrometer with a Nier-type ion source; metastable dissociation of anions and the kinetic energy release distribution (KERD) of the reactions are investigated by the mass analyzed ion kinetic energy (MIKE) technique.

The dependence of the metastable ion yield and the average KER on the electron energy are reported. For some reactions resonances in the metastable yield correlate with resonances in the yields of the corresponding prompt parent and fragment ions which suggests that some "prompt" ions (other than $\mathrm{DNB}^{-}$) result from fast metastable reactions in the ion source. The KER ranges from 0.06 to $1.32 \mathrm{eV}$. The dependence of the KER on the electron energy has been determined for reactions that exhibit multiple resonances. For (1,3-DNB$\mathrm{NO})^{-}$we identify a rarely observed sequential metastable reaction, namely, loss of NO followed by loss of $\mathrm{CO}$; the second step features a particularly large KER of $1.32 \mathrm{eV}$. Experimental data are augmented by $a b$ initio calculations using the G4(MP2) method; ${ }^{12}$ reaction energies of anions are presented for all isomers of DNB.

\section{EXPERIMENT}

This study explores the three structural isomers of dinitrobenzene $\left(\mathrm{C}_{6} \mathrm{H}_{4} \mathrm{~N}_{2} \mathrm{O}_{4}\right.$, DNB, nominal mass 168 u), i.e., 1,2DNB (ortho, CAS Number 528-29-0), 1,3-DNB (meta, CAS Number 99-65-0), and 1,4-DNB (para, CAS Number 10025-4). The compounds were purchased from Sigma Aldrich (stated purity $99.5 \%$ ) and used as delivered.

Two different experimental setups are used in our collaborative study. The Belfast apparatus includes a linear TOF mass spectrometer with a two-zone extraction region and a pulsed trochoidal electron monochromator (energy resolution $0.25 \mathrm{eV}$ at low energies). ${ }^{13}$ DNB was introduced to the apparatus through a short wide tube kept at room temperature. Ions are extracted $\sim 1 \mu$ s after the end of the electron pulse with a $\sim 200 \mathrm{~V} / \mathrm{cm}$ electric field; they pass through an acceleration region with a $\sim 400 \mathrm{~V} / \mathrm{cm}$ field before entering a field-free drift region.

The TOF spectrometer is sensitive to metastable dissociations that occur during acceleration of the ions. The corresponding time window for the reaction with respect to the ionizing electron pulse is $1 \mu \mathrm{s} \leq t \leq 3.1 \mu \mathrm{s}$ for prompt ions of mass $168 \mathrm{u}$. The lower limit is the time at which the ion extraction field is turned on; the upper limit is the time by which a stable ion will have fully traversed the two-zone extraction region (ions of mass $168 \mathrm{u}$ spend $1.4 \mu \mathrm{s}$ in the extraction region and $0.7 \mu \mathrm{s}$ in the acceleration region). If an ion of mass $m_{\mathrm{p}}$ dissociates during the metastable time window into an ion of mass $m_{\mathrm{f}}$, the fragment ion will have a flight time which lies between those of prompt, stable ions of mass $m_{\mathrm{f}}$ and $m_{\mathrm{p}}$, respectively. Dissociation in the interaction region gives flight times closer to that of a stable ion of mass $m_{\mathrm{f}}$; dissociation in the acceleration region gives flight times closer to that of a stable ion of mass $m_{\mathrm{p}}$. The metastable signal in the interaction region is stronger than in the acceleration region because (i) the average excitation energy of the ensemble of metastable ions, hence their dissociation rate, will decrease with increasing time, and (ii) the ions spend more time in the extraction than in the acceleration region. In fact, the experimental data reveal a step in the metastable signal intensity, approximately halfway between parent and fragment flight times, which corresponds to the cutoff between dissociation in the interaction region and dissociation in the acceleration region.

The Innsbruck apparatus consists of a high resolution double focusing two sector field mass spectrometer (VG-ZAB2) of reversed Nier-Johnson-type BE geometry. ${ }^{14}$ DNB is introduced into the collision chamber of the ion source through a capillary of $1 \mathrm{~mm}$ diameter. The gas inlet was heated to about $80^{\circ} \mathrm{C}$ to enhance the signal; the collision chamber was heated to $250^{\circ} \mathrm{C}$ to avoid surface contamination.

Anions are extracted from the Nier-type ion source (electron energy resolution $1 \mathrm{eV}$ at low energies) by a weak electric field and accelerated by a voltage drop of $7 \mathrm{kV}$ into the analyzer (pressure $4 \times 10^{-7} \mathrm{~Pa}$ ). Ions pass through the first fieldfree region (ff1), are momentum-analyzed by a $35^{\circ}$ magnetic sector field, pass through a second field-free region (ff2), are energy selected by a $81^{\circ}$ electric sector field, and are detected by a channeltron-type electron multiplier.

Ions will appear in the mass spectrum as "prompt" ions if they are formed in the ion source within less than about $4 \mu$ s. Metastable (i.e., unimolecular, spontaneous) decay of ions in the second field-free region is investigated by the MIKE technique. ${ }^{15,16}$ The corresponding time window for the reaction with respect to the ionization event is $13.2 \mu \mathrm{s} \leq t$ $\leq 29.7 \mu$ s (these values apply to parent anions of mass $168 \mathrm{u}$; they scale with the square root of the parent ion mass). MIKE spectra are recorded by tuning the magnet to transmit a specific parent ion of mass $m_{\mathrm{p}}$ and scanning the electric sector voltage $U$. If $U_{\mathrm{p}}$ denotes the voltage required to transmit a singly charged parent ion of mass $m_{\mathrm{p}}$ then the electric sector will transmit its fragment ion of mass $m_{\mathrm{f}}$, formed in ff2, if the sector field voltage is set to $U_{\mathrm{f}}=U_{\mathrm{p}} m_{\mathrm{f}} / m_{\mathrm{p}}$.

A double focusing two sector field mass spectrometer of reversed Nier-Johnson-type BE geometry may also be used to detect sequential metastable reactions, where a singly charged ion of mass $m_{\mathrm{p}}$ decays into an ion of mass $m_{1}$ in the ff1 region, followed by decay into an ion of mass $m_{2}$ in the ff 2 region. The reaction is detected by tuning the magnetic sector so that it would pass stable ions of mass $m_{1}{ }^{2} / m_{\mathrm{p}}$, and the electric sector to $U_{\mathrm{p}} m_{2} / m_{\mathrm{p}}$.

The kinetic energy released in a metastable reaction that occurs in ff2 will modify the shape of the metastable peak as recorded in a MIKE scan. Two commonly encountered peak shapes are (i) a Gaussian peak if the kinetic energy release follows a Maxwell-Boltzmann distribution, and (ii) a flat-topped peak with steep outer edges if the kinetic energy release has a narrow distribution. Flat-topped peaks will appear dished if the KER is large such that the finite length of the exit slit gives rise to strong discrimination against ions that are emitted with large z-components, i.e., along the direction of the slit. ${ }^{16}$

The KERD for a reaction that occurs in ff2 can be derived from the shape of a metastable fragment ion in a MIKE 
scan by taking the derivative of the fragment ion yield with respect to the electric sector field voltage, after deconvolution with the parent ion peak. ${ }^{16-18}$ The procedure is simpler and results are more robust if the MIKE peak is Gaussian. Either way, the average value of the KERD, $\bar{\varepsilon}$, may be extracted. Values given in this work have an accuracy of about $10 \%$ for Gaussian peaks; the accuracy for dished peaks is lower.

\section{RESULTS}

\section{A. Overview of experimental results}

Intact $\mathrm{DNB}^{-}$as well as several "prompt" fragment anions are observed when free electrons are attached to DNB in the gas phase; the prompt ion yields exhibit resonances ranging from 0 to $10 \mathrm{eV}^{11}$ Intact $\mathrm{DNB}^{-}$anions formed this way are metastable because they contain enough energy for the reverse reaction (autodetachment),

$$
\mathrm{DNB}+\mathrm{e} \rightarrow \mathrm{DNB}^{-*} \rightarrow \mathrm{DNB}+\mathrm{e} .
$$

In the present study we observe, in agreement with a report by Bowie, ${ }^{2}$ metastable loss of $\mathrm{NO}$ from $\mathrm{DNB}^{*-}$, i.e., dissociation (reaction 1) competes with autodetachment (reaction 2). In addition, we observe several metastable reactions of anions which result from dissociative electron attachment, namely,

$$
\begin{aligned}
& (\mathrm{DNB}-\mathrm{H})^{-} \rightarrow(\mathrm{DNB}-\mathrm{H}-\mathrm{NO})^{-}+\mathrm{NO}, \\
& \text { i.e., mass } 167 \mathrm{u} \rightarrow 137 \mathrm{u}, \\
& (\mathrm{DNB}-\mathrm{NO})^{-} \rightarrow(\mathrm{DNB}-2 \mathrm{NO})^{-}+\mathrm{NO}, \\
& \quad \text { i.e., mass } 138 \mathrm{u} \rightarrow 108 \mathrm{u}, \\
& (\mathrm{DNB}-2 \mathrm{NO})^{-} \rightarrow(\mathrm{DNB}-2 \mathrm{NO}-\mathrm{CO})^{-}+\mathrm{CO}, \\
& \text { i.e., mass } 108 \mathrm{u} \rightarrow 80 \mathrm{u}, \\
& \left(\mathrm{DNB}-\mathrm{NO}_{2}\right)^{-} \rightarrow\left(\mathrm{DNB}-\mathrm{NO}_{2}-\mathrm{NO}\right)^{-}+\mathrm{NO}, \\
& \text { i.e., mass } 122 \mathrm{u} \rightarrow 92 \mathrm{u} .
\end{aligned}
$$

All these reactions are unimolecular; the low pressure in the instrument, $4 \times 10^{-7} \mathrm{~Pa}$, ensures minimal interference from collision induced fragmentation (the collision frequency of DNB with residual gas is about $1 / \mathrm{s}$ ). Some of these metastable reactions exhibit multiple resonances in their yield versus electron energy; the resonances depend on the isomeric structure of the neutral precursor. The average KER of some reactions shows a strong dependence on the electron energy.

Furthermore, a rare example of a sequential (consecutive) metastable reaction has been identified, namely,

$$
\begin{aligned}
& (\mathrm{DNB}-\mathrm{NO})^{-} \rightarrow(\mathrm{DNB}-2 \mathrm{NO})^{-} \\
& \quad+\mathrm{NO} \rightarrow(\mathrm{DNB}-2 \mathrm{NO}-\mathrm{CO})^{-}+\mathrm{NO}+\mathrm{CO}, \\
& \text { i.e., mass } 138 \mathrm{u} \rightarrow 108 \mathrm{u} \rightarrow 80 \mathrm{u} .
\end{aligned}
$$

The metastable intensity for reaction 7 is weak; it could only be identified for 1,3-DNB.

\section{B. Time-of-flight data}

Figure 1 displays TOF data for 1,3-DNB. Electron energies are plotted along the ordinate, the time-of-flight of anions

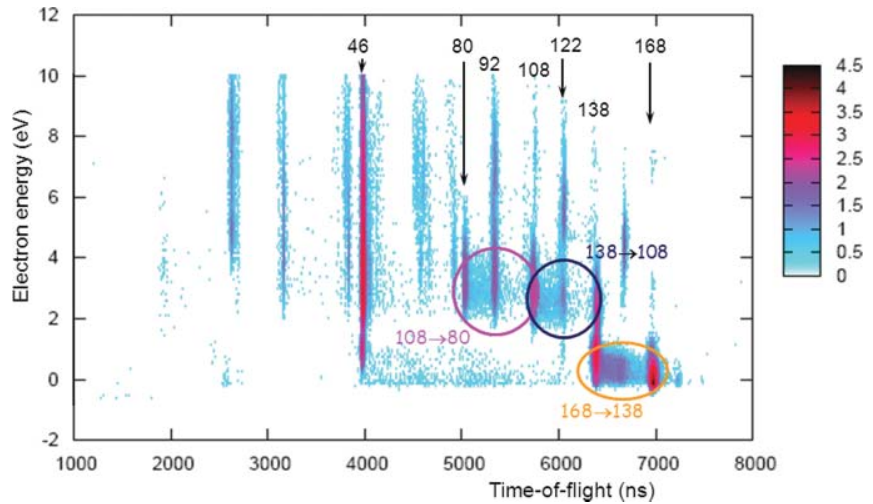

FIG. 1. Time-of-flight (TOF) data obtained for electron attachment to 1,3dinitrobenzene (DNB, mass $168 \mathrm{u}$ ). Regions that reveal particularly strong metastable ion activity are circled.

is plotted along the abscissa, and ion intensities are shown on a logarithmic scale. Narrow vertical bands arise from prompt ions, i.e., ions that were formed within $<1 \mu$ s and did not dissociate in the metastable time window, i.e., during acceleration. Their masses can be computed unambiguously from their TOF; some values are indicated in Fig. 1. The focus of the current work are intact ions of DNB at $168 \mathrm{u}$ and prompt fragment ions at mass $138,122,108$, and $80 \mathrm{u}$, formed by the loss of $\mathrm{NO}, \mathrm{NO}_{2}, 2 \mathrm{NO}$, and $2 \mathrm{NO}+\mathrm{CO}$, respectively. Ions separated by only $1 \mathrm{u}$ are not resolved in this data set due to kinetic energy release broadening. Measurements with the double focusing two sector field mass spectrometer, discussed below, reveal the presence of ions of mass 167 and $137 \mathrm{u}$, due to the loss of $\mathrm{H}$ and $\mathrm{H}+\mathrm{NO}$, respectively. ${ }^{19}$

The intensity distribution within a vertical band shows the dependence of the anion yield on the electron energy. For example, ions of mass $168 \mathrm{u}$ (and/or $167 \mathrm{u}$ ) are preferentially formed within a narrow energy range near $0 \mathrm{eV}$, while ions of mass $92 \mathrm{u}$ are preferentially formed between 2 and $5 \mathrm{eV}$, with a long tail toward higher energies. The energy dependence of prompt ions formed upon electron attachment to DNB has been measured previously at a resolution of $0.1 \mathrm{eV}^{11}$

The TOF of ions of mass $m_{\mathrm{f}}$ that are formed by dissociation of ions of mass $m_{\mathrm{p}}$ in the metastable time window lies between the TOF of prompt, stable ions of mass $m_{\mathrm{f}}$ and $m_{\mathrm{p}}$; most of the metastable intensity will occur just to the right of the fragment ion peak (mass $m_{\mathrm{f}}$ ). Figure 1 thus provides clear evidence for metastable dissociation of mass 168 (or 167) into 138 (or 137) u. The probability is highest near zero electron energies. Metastable dissociation of mass 138 into $108 \mathrm{u}$ is most probable around $3 \mathrm{eV}$, and metastable dissociation of 108 into $80 \mathrm{u}$ reaches a maximum just above $3 \mathrm{eV}$.

\section{Metastable ion yields measured with the two sector field mass spectrometer}

MIKE spectra recorded with the double focusing two sector field mass spectrometer reveal the presence of metastable reactions 1 and 3 through 6 . Recording MIKE spectra is more time-consuming than the TOF technique but the results are essentially immune to contamination ${ }^{19}$ from multiple reaction 


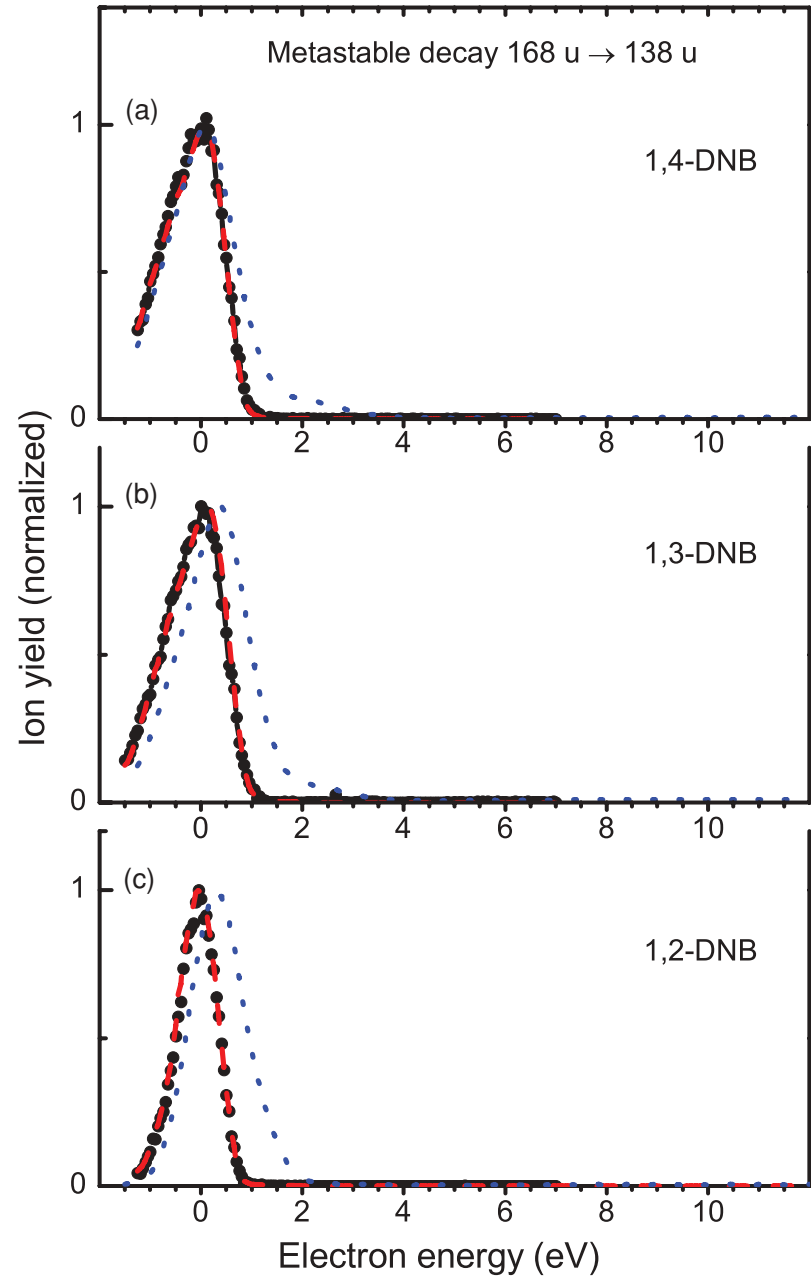

FIG. 2. Energy dependence of the probability for reaction 1, metastable dissociation of $\mathrm{DNB}^{-}$anions at mass $168 \mathrm{u}$ into anions of $138 \mathrm{u}$ (solid dots), and of the corresponding prompt ions (dashed and dotted lines), for the three isomers of DNB.

channels because specific parent ions are selected by the magnet with high mass resolution.

The dependence of the metastable ion yield on the electron energy $E_{\mathrm{e}}$ is obtained by tuning the magnet to transmit the parent ion of mass $m_{\mathrm{p}}$, and the electric sector to transmit a specific fragment ion of mass $m_{\mathrm{f}}$ that is produced from the parent in the second field-free region. Data are recorded for reactions 1 and 3 through 6; results are presented in Figs. 2-6. For comparison, each panel also shows the yield of the corresponding prompt, stable ions of mass $m_{\mathrm{p}}$ and $m_{\mathrm{f}}$ (dashed and dotted curves, respectively). The energy resolution of the measurements is $1 \mathrm{eV}$; measurements of prompt, stable ions at higher electron energy resolution with a different instrument have been reported elsewhere. ${ }^{11}$ For better visibility, all spectra are normalized to the same height; absolute ion yields are listed in Table I. The low-energy region of reaction 3 is contaminated by the strong zero-eV resonance of reaction 1; data in this range $\left(E_{\mathrm{e}}<1.5 \mathrm{eV}\right)$ are omitted from Fig. 3.

The normalized yield of the sequential reaction 7 is displayed in Fig. 7. The reaction is identified by tuning the magnetic sector to a mass $108^{2} / 138 \mathrm{u}$; at this value ions that

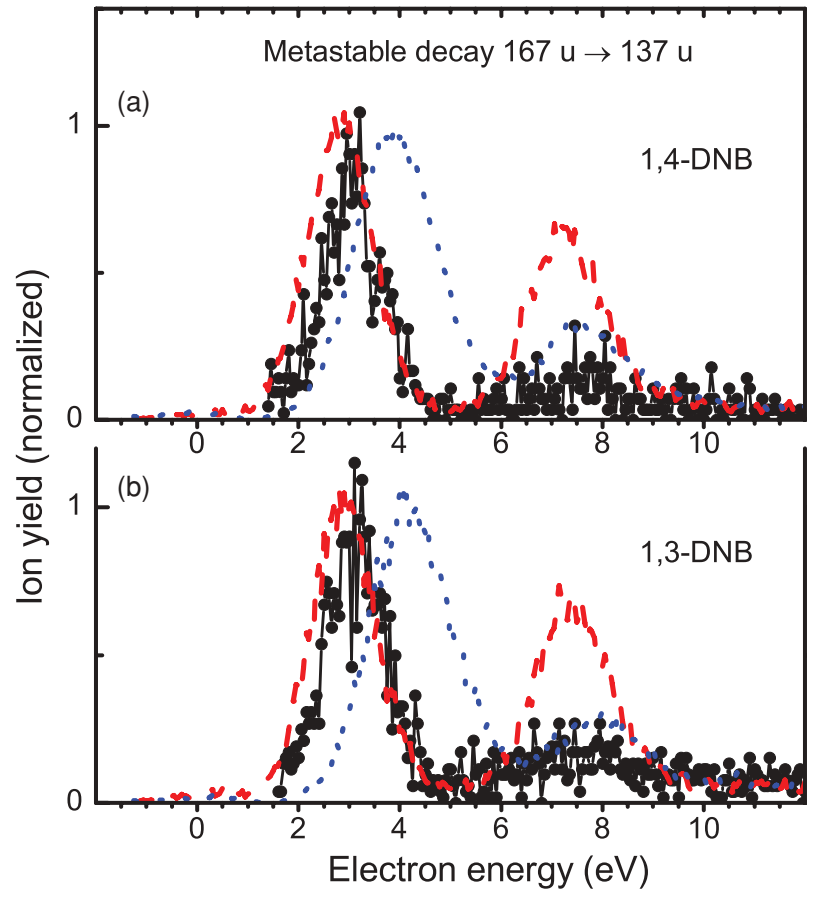

FIG. 3. Energy dependence of the probability for reaction 3, metastable dissociation of mass $167 \mathrm{u}$ anions (DNB-H) ${ }^{-}$into $137 \mathrm{u}$ (solid dots), and of the corresponding prompt ions (dashed and dotted lines).

change mass from 138 to $108 \mathrm{u}$ in the first field-free region will pass through the magnet. The electric sector is set to transmit $80 \mathrm{u}$ fragment ions that are then produced in ff 2 . The metastable yield is low; it could be identified only for the 1,3DNB isomer.

Metastable signals displayed in Figs. 2-7 exhibit a wide range of patterns; they will be discussed in Sec. IV.

\section{Metastable peak shapes and kinetic energy release}

The yields of metastable ions shown in Figs. 2-7 were recorded by setting the electric sector field to $U_{\mathrm{f}}=U_{\mathrm{p}} m_{\mathrm{f}} / m_{\mathrm{p}}$ as explained in Sec. II, and recording the ion yield as a function of the electron energy. Another important piece of information may be deduced from the shape of the metastable ion peak which is obtained from MIKE scans, by tuning the electric sector field while keeping other parameters fixed. Three such data sets are displayed in Fig. 8, a MIKE scan for the sequential loss of $\mathrm{NO}$ and $\mathrm{CO}$ from 1,3-(DNB-NO) ${ }^{-}$(reaction 7), a MIKE scan for loss of NO from 1,4-DNB ${ }^{-}$(reaction 1), and a MIKE scan for loss of NO from 1,2-(DNB-NO $\left.{ }_{2}\right)^{-}$ (reaction 6). The centroids of the metastable ion peaks are at $U_{\mathrm{f}} / U_{\mathrm{p}}=80 / 108,138 / 168$, and $92 / 122$, respectively. The metastable peaks are broader than the corresponding parent ion peaks which appear at $U_{\mathrm{f}} / U_{\mathrm{p}}=1$.

For reactions 7 and 1 [Figs. 8(a) and 8(b), respectively] the metastable peak is very broad and dished; this shape is characteristic of a large average KER with a relatively narrow distribution. For reaction 6 [Fig. 8(c)] the metastable peak is Gaussian, characteristic of a Maxwell-Boltzmann distribution for the KER. We extract the KER distributions from the data in Figs. 8(b) and 8(c) [data in Fig. 8(a) are too noisy] by 


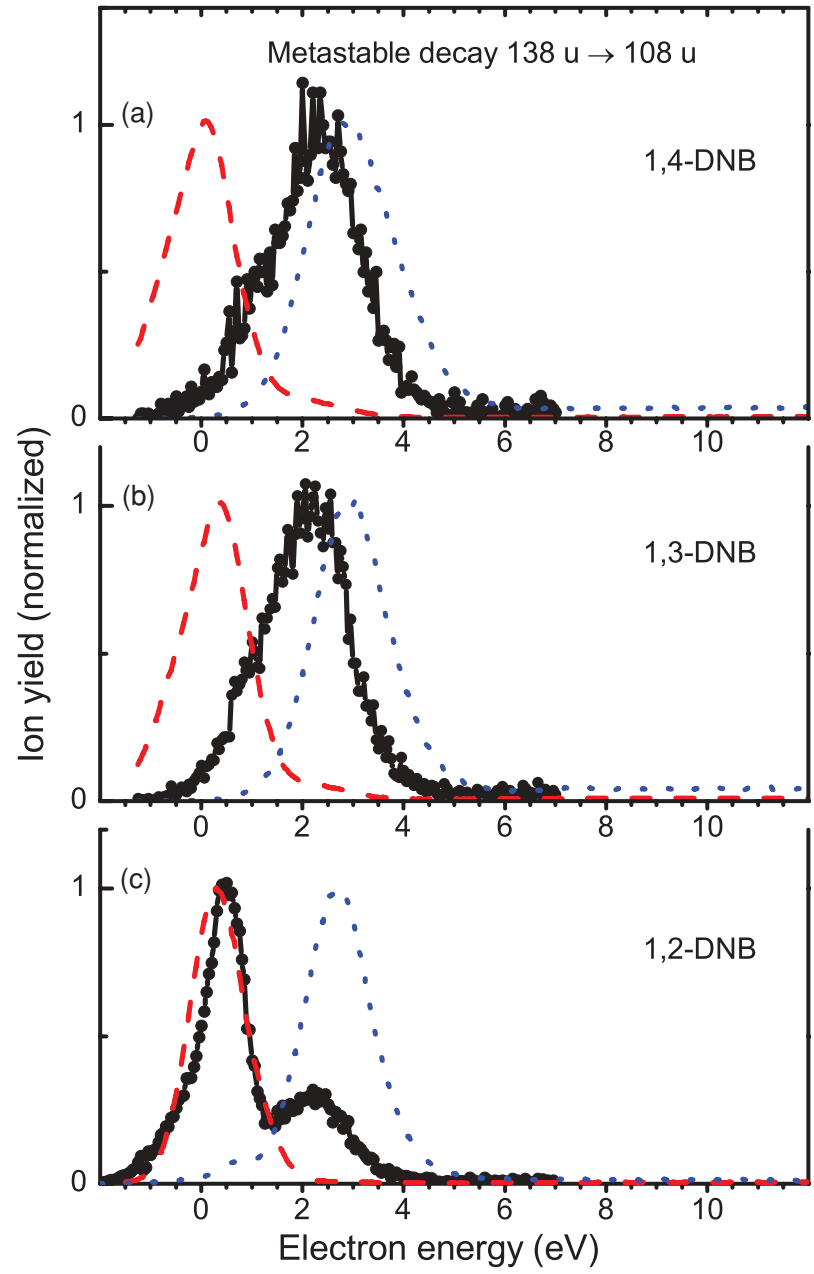

FIG. 4. Energy dependence of the probability for reaction 4, metastable dissociation of mass $138 \mathrm{u}$ anions (DNB-NO)- into $108 \mathrm{u}$ (solid dots), and of the corresponding prompt ions (dashed and dotted lines).

applying the standard procedure of evaluating MIKE spectra which consists of (i) removing statistical noise, (ii) deconvoluting the fragment ion peak with the parent ion peak, (iii) differentiating the signal with respect to the sector field voltage, and (iv) transforming the sector-field voltage scale to the kinetic energy scale. ${ }^{17,20}$ The resulting KER distribu-

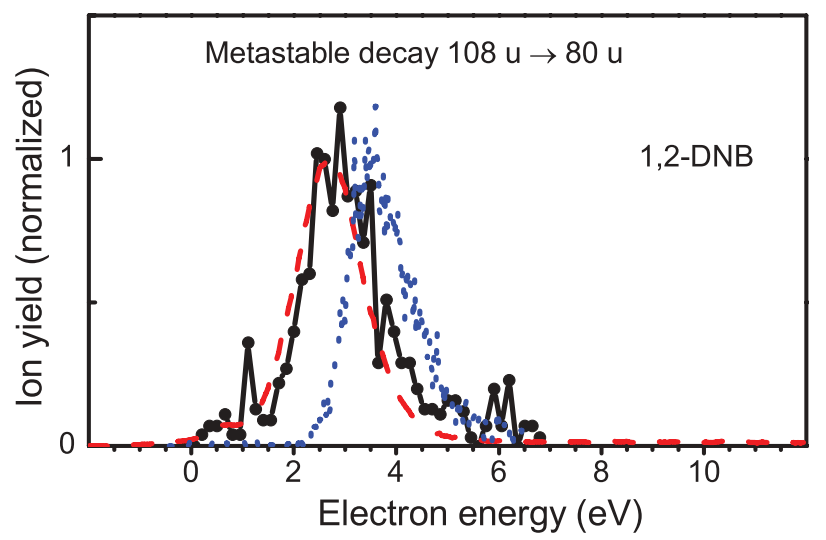

FIG. 5. Energy dependence of the probability for reaction 5, metastable dissociation of mass $108 \mathrm{u}$ anions (DNB-2NO) ${ }^{-}$into $80 \mathrm{u}$ (solid dots), and of the corresponding prompt ions (dashed and dotted lines).

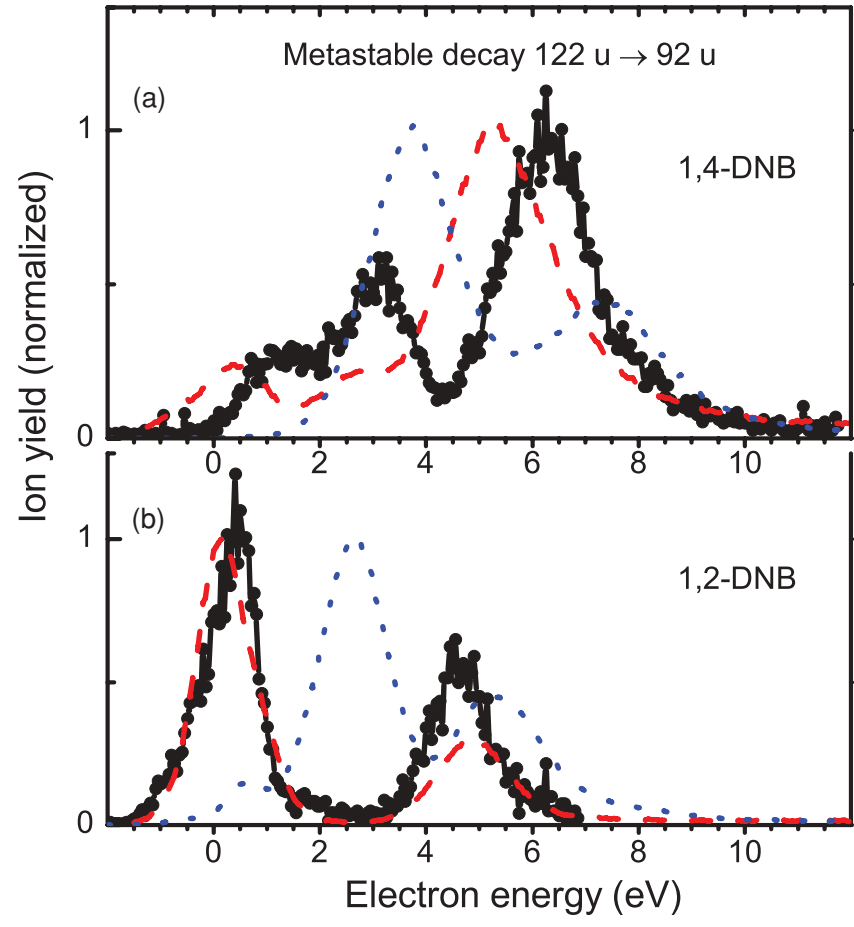

FIG. 6. Energy dependence of the probability for reaction 6, metastable dissociation of mass $122 \mathrm{u}$ anions $\left(\mathrm{DNB}-\mathrm{NO}_{2}\right)^{-}$into $92 \mathrm{u}$ (solid dots), and of the corresponding prompt ions (dashed and dotted lines).

tions are shown in Fig. 8(d). The MIKE peak in panel 8(b) corresponds to a distribution that peaks at $0.8 \mathrm{eV}$; the average value is $1.02 \mathrm{eV}$. This value is even larger than the KER found for metastable loss of NO from 2,4-dinitrotoluene after lowenergy electron attachment, which was $0.7 \mathrm{eV} .{ }^{9}$ The MIKE peak in Fig. 8(c) corresponds to a much narrower MaxwellBoltzmann-type KER distribution; the average KER is only $0.13 \mathrm{eV}$.

We have recorded MIKE spectra for all metastable reactions. The results of the analysis are listed in Table II; the electron energies were tuned to the corresponding resonances. For ions that feature multiple resonances (reactions 4 and 6), MIKE spectra were recorded for each resonance. The differences in the average KER can be large, i.e., for metastable loss of CO from $\left(1,4-\mathrm{DNB}-\mathrm{NO}_{2}\right)^{-}$(reaction 6, Fig. 6) we find values of $0.24,0.62$, and $0.31 \mathrm{eV}$ for the resonances at 1.25, 3.15 , and $6.25 \mathrm{eV}$, respectively.

\section{E. Computational study of DNB anions and their fragments}

For all calculations the GAUSSIAN 03 and GAUSSIAN 09 programs $^{21}$ have been used. The optimization of the structure of the neutral DNB's was performed with Hartree-Fock wavefunctions and Dunning's correlation consistent basis set, polarized valence triple-zeta (cc-pvtz). ${ }^{22}$ For the total energies and also the optimized geometries of the anions high level $a b$ initio calculations using the G4(MP2) method ${ }^{12}$ have been carried out. For 1,3-DNB and 1,4-DNB the structures with the lowest total energy (electronic + zero point energy) have all atoms in-plane. This is not so for 1,2-DNB; in its global energy minimum one nitro-group is rotated around its 
TABLE I. Ion yields $(\mathrm{kHz})$ for the various reactions for prompt, stable parents $(\mathrm{P})$, fragments $(\mathrm{F})$, and the metastable signal $(\mathrm{M})$. For the sequential reaction of 1,3-DNB, the two prompt fragment ions at 108 and $80 \mathrm{u}$ are identified as F1 and F2, respectively.

\begin{tabular}{|c|c|c|c|c|c|c|c|c|c|c|}
\hline \multirow[b]{2}{*}{ Reaction } & \multirow[b]{2}{*}{ Ion mass (u) } & \multicolumn{3}{|c|}{ 1,2-DNB } & \multicolumn{3}{|c|}{$1,3-\mathrm{DNB}$} & \multicolumn{3}{|c|}{ 1,4-DNB } \\
\hline & & $\mathrm{P}$ & $\mathrm{F}$ & M & $\mathrm{P}$ & F & M & $\mathrm{P}$ & $\mathrm{F}$ & M \\
\hline 1 & $168 \rightarrow 138$ & 32 & 58 & 1 & 130 & 210 & 0.7 & 160 & 230 & 0.95 \\
\hline 3 & $167 \rightarrow 137$ & - & - & & 0.21 & 0.53 & 0.009 & 0.7 & 0.62 & 0.008 \\
\hline 4 & $138 \rightarrow 108$ & 58 & 19 & 0.055 & 210 & 12 & 0.022 & 230 & 20 & 0.015 \\
\hline 5 & $108 \rightarrow 80$ & 19 & 5 & 0.0025 & & & & & & \\
\hline 6 & $122 \rightarrow 92$ & 5.6 & 26 & 0.061 & & & & 8.9 & 9.3 & 0.017 \\
\hline 7 (1,3-DNB) & \multicolumn{2}{|c|}{$138 \rightarrow 108 \rightarrow 80$} & \multicolumn{2}{|c|}{$210(\mathrm{P})$} & \multicolumn{2}{|c|}{$12(\mathrm{~F} 1)$} & \multicolumn{2}{|c|}{$5.5(\mathrm{~F} 2)$} & \multicolumn{2}{|c|}{$0.001(\mathrm{M})$} \\
\hline
\end{tabular}

CN-bond by about $39.1^{\circ}$ and the other one by about $40.9^{\circ}$. All isomers have positive adiabatic electron affinities; their values are $1.74 \mathrm{eV}$ for 1,2-DNB, $1.70 \mathrm{eV}$ for 1,3-DNB, and $2.14 \mathrm{eV}$ for 1,4-DNB, respectively, with an uncertainty of $\pm 0.10 \mathrm{eV}^{12}$ The values are listed in Table III together with experimental values ${ }^{6,7}$ which have estimated uncertainties of $0.1 \mathrm{eV}^{8}$ Theory and experiment agree within these uncertainties. The agreement is much more convincing than in previous work ${ }^{11}$ where electron affinities were derived via the G2(MP2) method, due to the higher level of theory used in the post-Hartree-Fock calculation steps and the enhanced extrapolation scheme of the new G4(MP2) method.

The energetics of fragment anions that are formed in reactions 1, 4, and 5 were computed as well. Table III lists adiabatic electron affinities of the corresponding neutrals, together with available experimental values. The computed AEA of 1,4-DNB-2NO (p-benzoquinone) agree quite well with the

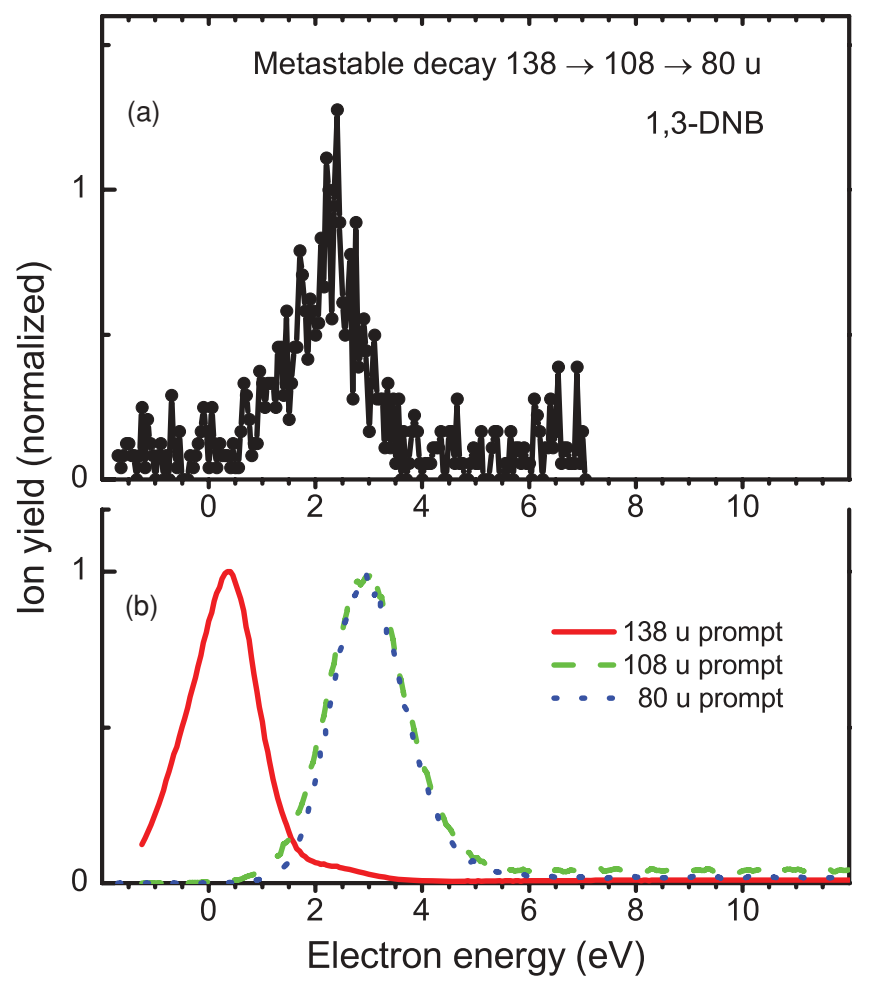

FIG. 7. Panel a: Energy dependence of the probability for reaction 7, sequential metastable loss of NO and CO from (DNB-NO) ${ }^{-}$. Panel b shows prompt ion yields at 138,108 , and $80 \mathrm{u}$ for comparison. experimental value of $1.860 \pm 0.001 \mathrm{eV} ;{ }^{24}$ the agreement is less satisfying for 1,2-DNB-2NO (o-benzoquinone).

The energies of anion fragments + neutrals relative to DNB plus a free electron are listed in Table IV and graphed in Fig. 9; optimized structures of 1,2-DNB and its fragment anions are also shown in Fig. 9. From the values in Table IV we obtain the energies $\Delta E_{\mathrm{th}}$ for reactions 1,4 , and 5; they are

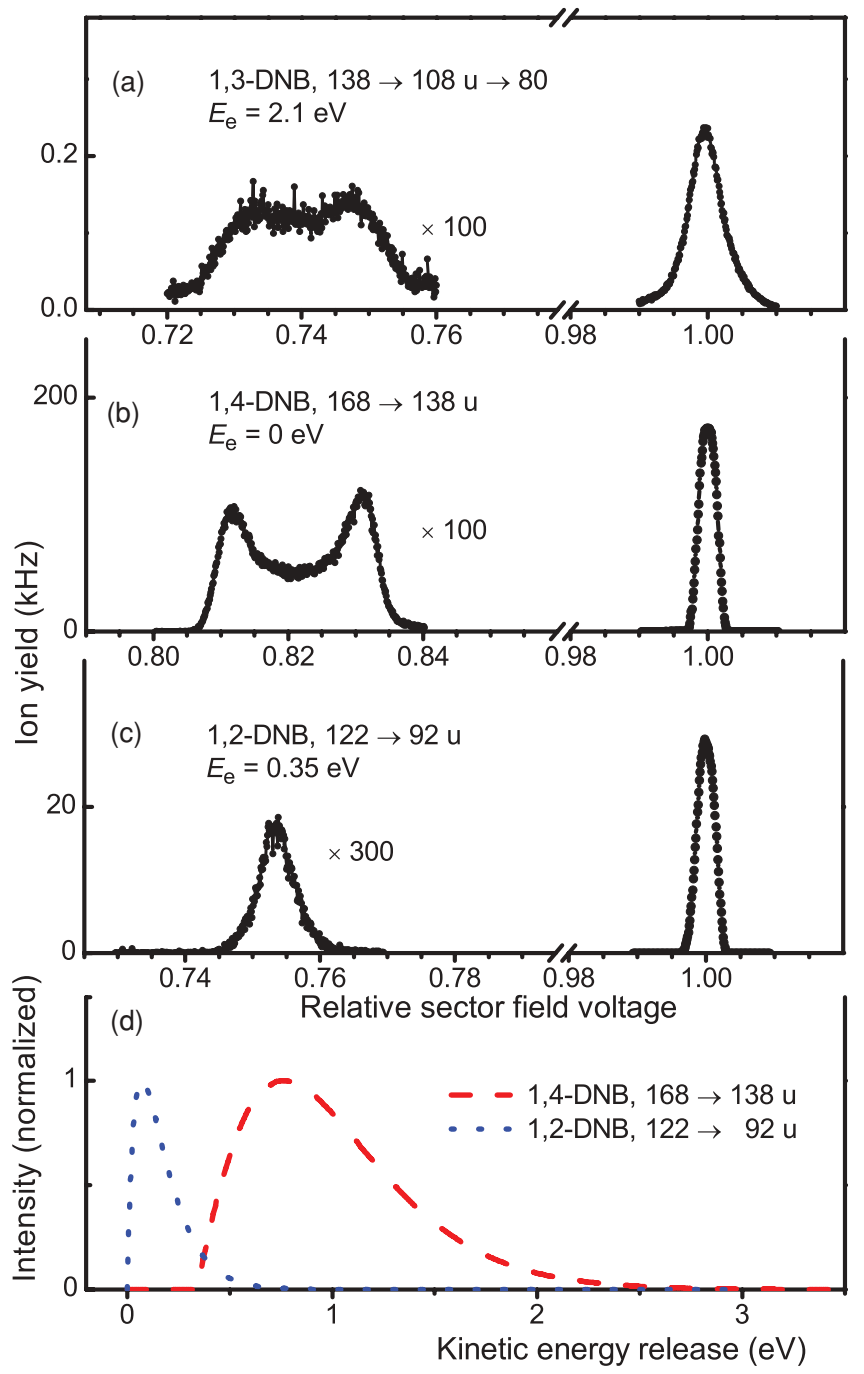

FIG. 8. MIKE scans for the sequential metastable reaction \#7 (panel a), reaction 1 (1,4-DNB, panel b), and reaction 6 (1,2-DNB, panel c). Panel d shows the kinetic energy release distributions extracted from the MIKE peaks in panels $b$ and $c$ (dashed and dotted lines, respectively). 
TABLE II. Average kinetic energy release for metastable reactions 1 and 3-7, for attachment of electrons at energy $E_{\mathrm{e}}$. Also listed are computed reaction energies $\Delta E_{\mathrm{th}}$. All energies are in $\mathrm{eV}$. The yield of reactions 3, 6, and 7 was below the detection limit for some isomers.

\begin{tabular}{|c|c|c|c|c|c|c|c|c|c|c|}
\hline \multirow[b]{2}{*}{ Reaction } & \multirow[b]{2}{*}{ Ion mass $(\mathrm{u})$} & \multicolumn{3}{|c|}{$1,2-\mathrm{DNB}$} & \multicolumn{3}{|c|}{ 1,3-DNB } & \multicolumn{3}{|c|}{ 1,4-DNB } \\
\hline & & KER & $E_{\mathrm{e}}$ & $\Delta E_{\mathrm{th}}$ & KER & $E_{\mathrm{e}}$ & $\Delta E_{\text {th }}$ & KER & $E_{\mathrm{e}}$ & $\Delta E_{\mathrm{th}}$ \\
\hline 1 & $168 \rightarrow 138$ & 1.01 & 0 & -0.76 & 0.89 & 0 & -0.53 & 1.02 & 0 & -0.41 \\
\hline 3 & $167 \rightarrow 137$ & - & - & & 0.06 & 3.2 & & 0.10 & 3.2 & \\
\hline 4 & $138 \rightarrow 108$ & $0.95,1.31$ & $0.45,2.85$ & 0.39 & 0.68 & 2.1 & 0.80 & 0.69 & 2.3 & 0.53 \\
\hline 5 & $108 \rightarrow 80$ & 0.93 & 2.9 & 1.08 & 0.91 & 3 & 0.74 & 0.79 & 3 & 1.33 \\
\hline 6 & $122 \rightarrow 92$ & $0.13,0.17$ & $0.35,4.65$ & & - & - & & $0.24,0.62,0.31$ & $1.25,3.15,6.25$ & \\
\hline 7 & $138 \rightarrow 108 \rightarrow 80$ & - & - & & $1.32^{\mathrm{a}}$ & 2.1 & & - & - & \\
\hline
\end{tabular}

${ }^{\text {a }}$ The value refers to the second step of the sequential reaction.

listed in Table II. Loss of one NO from $\mathrm{DNB}^{-}$is exothermic. Loss of a second $\mathrm{NO}$ and subsequent loss of $\mathrm{CO}$ are endothermic. Sulzer et al. ${ }^{11}$ estimated that loss of two NO from $\mathrm{DNB}^{-}$is exothermic by about $1.5 \mathrm{eV}$. We find a much smaller exothermicity of only $0.37 \mathrm{eV}$ for 1,2-DNB; for the other isomers the reaction becomes endothermic. Still, it is remarkable that the total energy of $\mathrm{C}_{5} \mathrm{H}_{4} \mathrm{O}^{-}+2 \mathrm{NO}+\mathrm{CO}$ is $1.03 \mathrm{eV}$ below 1,2-DNB plus a free electron, and $0.69 \mathrm{eV}$ below 1,3-DNB or 1,4-DNB plus a free electron.

\section{DISCUSSION}

In a previous publication we presented the yield of "prompt" anions that result from electron attachment to the isomers of DNB versus electron energy. ${ }^{11}$ The data showed a rich spectrum of isomer-specific resonances between 0 and $10 \mathrm{eV}$. Resonant formation of $\mathrm{DNB}^{-}$at $0 \mathrm{eV}$ probably proceeds through the electronic ground state of the anion; quantum chemical calculations show that the lowest unoccupied orbital of neutral DNB does not change qualitatively upon accommodating the additional electron of the anion. ${ }^{11}$ Low-lying resonances in the yield of prompt fragment anions are probably also due to single particle shape resonances whereas higher-lying resonances are probably due to Feshbach resonances, i.e., processes that involve electronic excitations of the target molecule.

The present data show a similarly rich spectrum of resonances in the yield of metastable anions that are highly isomer-specific. A comparison of resonances in the metastable ion yields with resonances in the corresponding

TABLE III. Computed adiabatic electron effinities of DNB and its fragments, in $\mathrm{eV}$, together with some experimental values. Estimated uncertainties of experimental values for DNB are $0.01 \mathrm{eV}$ (Ref. 8).

\begin{tabular}{lccc}
\hline \hline Product & $1,2-\mathrm{DNB}$ & $1,3-\mathrm{DNB}$ & $1,4-\mathrm{DNB}$ \\
\hline DNB & 1.74 & 1.70 & 2.14 \\
DNB (experiment) & $1.65^{\mathrm{a}}$ & $1.65^{\mathrm{a}}$ & $2.00^{\mathrm{a}}$ \\
DNB-NO & 3.16 & 3.03 & 3.33 \\
DNB-2NO & 2.09 & 2.19 & 2.02 \\
DNB-2NO (experiment) & $1.620 \pm 0.048^{\mathrm{b}}$ & & $1.860 \pm 0.005^{\mathrm{c}}$ \\
DNB-2NO-CO & & 1.20 & \\
\hline \hline
\end{tabular}

${ }^{\mathrm{a}}$ Reference 6.

${ }^{\mathrm{b}}$ Reference 23 .

${ }^{\mathrm{c}}$ Reference 24 prompt, stable parent and fragment ions displays a wide range of patterns. We reiterate that any fragment ions formed in the ion source within less than $4 \mu$ s will appear as "prompt" ions because they will have acquired the full energy of $7 \mathrm{keV}$ upon acceleration. Prompt ions other than $\mathrm{DNB}^{-}$may well result from fast metastable dissociation within the ion source because energy randomization requires much less than $4 \mu \mathrm{s}$. Hence, for a given reaction, "prompt" stable parent and fragment ions (e.g., ions of mass 138 and $108 \mathrm{u}$ for reaction 4, Fig. 4) are ions that were formed within the ion source within less than $4 \mu$ s and remained stable until they hit the detector, while "metastable ions" were formed from "prompt" parent ions of mass $138 \mathrm{u}$ in the second field-free region $(12.0 \mu \mathrm{s}$ $\leq t \leq 26.9 \mu$ s for mass $138 \mathrm{u}$ ).

One may thus expect that the metastable signal tracks resonances in the parent ion signal, because a resonance in the latter implies that a maximum number of ions will enter the field-free region. After all, if no parent ions enter ff 2 , the metastable signal will be zero. This kind of tracking is seen indeed for reaction 1 (Fig. 2), loss of $\mathrm{NO}$ from $\mathrm{DNB}^{-}$, where parent, fragment, and metastable ion all feature a single resonance near $0 \mathrm{eV}$. A similar pattern is observed for reaction 5 (Fig. 5) in 1,2-DNB where the metastable signal closely tracks the resonance of the parent ion signal at $3 \mathrm{eV}$. For both reactions, the corresponding prompt fragment ion resonance is slightly shifted upward. This pattern suggests that all anions (metastable as well as prompt parent and fragment) are formed via the same electronic state of the parent ion, and that prompt as well as metastable dissociation result from vibrational predissociation, occurring after complete randomization of the excess energy over all energetically accessible modes. In this scenario, attachment of electrons of relatively low energy (but within the Frank Condon region of the resonance) will favor parent ions, i.e., ions whose lifetime exceeds the time-of-flight to the detector (about $40 \mu \mathrm{s}$ for $\mathrm{DNB}^{-}$).

TABLE IV. Computed energies of DNB anions and their fragments relative to neutral DNB plus a free electron. Estimated uncertainties are $0.10 \mathrm{eV}$.

\begin{tabular}{lccc}
\hline \hline Product & $1,2-\mathrm{DNB}$ & $1,3-\mathrm{DNB}$ & $1,4-\mathrm{DNB}$ \\
\hline $\mathrm{DNB}^{-}$ & -1.74 & -1.70 & -2.14 \\
(DNB-NO) $^{-}+\mathrm{NO}$ & -2.50 & -2.23 & -2.55 \\
(DNB-2NO $^{-}+2 \mathrm{NO}$ & -2.11 & -1.43 & -2.02 \\
(DNB-2NO-CO $^{-}+2 \mathrm{NO}+\mathrm{CO}$ & -1.03 & -0.69 & -0.69 \\
\hline \hline
\end{tabular}




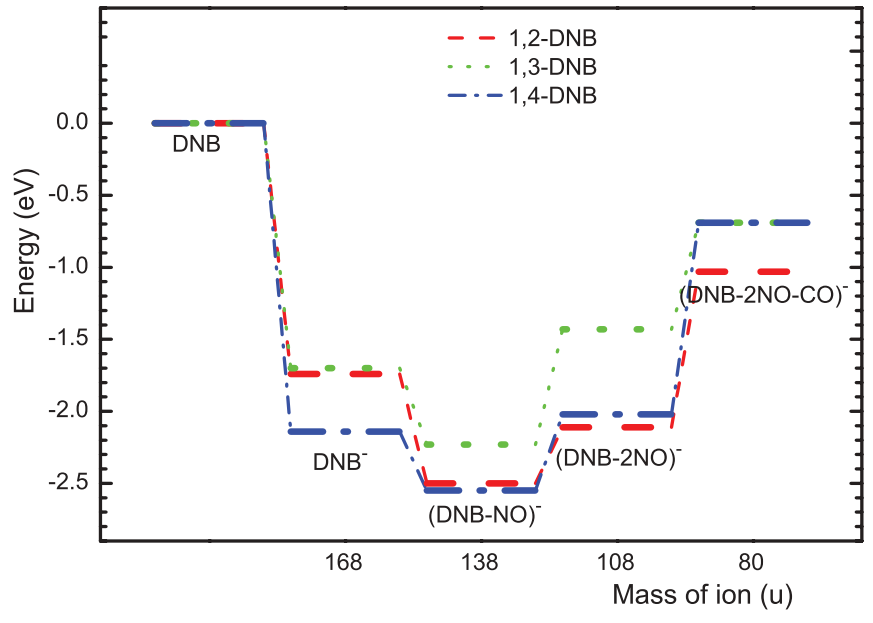

FIG. 9. Energetics of the three isomers of $\mathrm{DNB}, \mathrm{DNB}^{-}$, and their fragment anions, computed with the G4(MP2) method. Molecular structures are shown for the 1,2-DNB isomer.

On the other hand, relatively high electron energy within the Frank Condon region favors "prompt" fragment ions, i.e., the formation of parent ions whose dissociation rate coefficient exceeds the inverse ion extraction time which is roughly $4 \mu \mathrm{s}$.

The same argument rationalizes the complex pattern observed for reaction 6 (Fig. 6) of the 1,4-DNB isomer. The metastable ion yield exhibits three resonances, at 1.25, 3.15, and $6.25 \mathrm{eV}$. The three resonances in the prompt parent ion yield are redshifted by 0.5 to $1 \mathrm{eV}$ while the prompt fragment ion exhibits two resonances that are blueshifted by about 1 $\mathrm{eV}$ relative to the upper two resonances in the metastable ion yield.

The energetic blueshift between the metastable ion and prompt fragment ion for reaction 4 (Fig. 4), isomers 1,3-DNB and 1,4-DNB, shows a similar trend. However, in this case the energy difference between the resonances in the metastable ion and the parent ion is large, about $2 \mathrm{eV}$; the attachment possibly involves different anion states. A different situation is encountered for the 1,2-DNB isomer where the metastable ion exhibits two resonances, one at $0 \mathrm{eV}$ coinciding with the parent ion resonance, and one at $\approx 2.5 \mathrm{eV}$ coinciding with the fragment ion resonance.

Reactions 4 and 6 (Figs. 4 and 6, respectively) exhibit a striking difference between 1,2-DNB and the other isomers. The difference is likely due to the different geometries. While for 1,3-DNB and 1,4-DNB all atoms are in one plane, this is not the case for 1,2-DNB. For mass $108 \mathrm{u}$ the two oxygen atoms in ortho-position are tilted out of the plane of the carbon atoms to the opposite sites; for mass $138 \mathrm{u}$ the two nitro-groups are not in plane. When one of the nitro-groups is removed, there is still a coupling between the $\pi$-orbitals of the benzene ring and the $\sigma$-orbitals of the nitro-group, which leads to significantly enhanced dissociation reactions in comparison to corresponding fragments of 1,3-DNB and 1,4-DNB in the metastable regime.

We now turn to a discussion of the measured kinetic energy release. The $3.2 \mathrm{eV}$ resonance for reaction 3 (Fig. 3) coincides with the first resonance in the yield of prompt parent ions $(\mathrm{DNB}-\mathrm{H})^{-}$; the small value of the KER suggests a

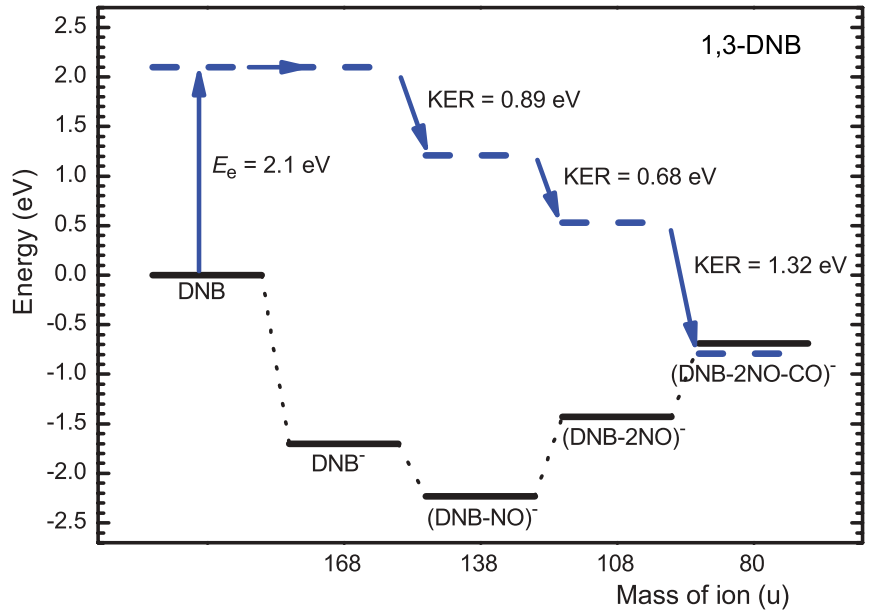

FIG. 10. Energetics estimated with the help of experimental and computational data for reaction 7, electron attachment to $1,3-\mathrm{DNB}$ at $2.1 \mathrm{eV}$ resulting in $\mathrm{C}_{5} \mathrm{H}_{4} \mathrm{O}^{-}$via sequential loss of $\mathrm{NO}+\mathrm{NO}+\mathrm{CO}$.

simple bond cleavage reaction. ${ }^{2}$ Most of the other metastable reactions, however, feature larger KER values that range from $\approx 0.5 \mathrm{eV}$ to $\approx 1.3 \mathrm{eV}$. This result is hardly surprising for reactions $1,4,5$, and 7 which involve multiple bond cleavage and structural and electronic rearrangement, leading to reverse activation barriers that are reflected in the kinetic energy distributions. More surprising is the low KER for NO loss from (DNB-H) ${ }^{-}$discussed above, and for reaction 6 (Fig. 6), loss of $\mathrm{NO}$ from $\left(\mathrm{DNB}-\mathrm{NO}_{2}\right)^{-}$.

How can one reconcile large KER values with strong fragmentation in endothermic channels such as loss of $\mathrm{NO}$ and then $\mathrm{CO}$ from (DNB-NO) ${ }^{-}$? Figure 10 illustrates the energetics of forming 2,4-cyclopentadiene-1-one anions, $\left(\mathrm{C}_{5} \mathrm{H}_{4} \mathrm{O}\right)^{-}$, from 1,3-DNB plus a free electron via reaction 7 (Fig. 7), prompt loss of NO followed by sequential metastable loss of $\mathrm{NO}$ and then $\mathrm{CO}$, for the $2.1 \mathrm{eV}$ resonance. Solid lines indicate the computed energies of the anions relative to DNB $+\mathrm{e}^{-}$in their respective ground states (Table IV). Total energies (dashed lines) are estimated from experimental data as follows. Attachment of an electron at $2.1 \mathrm{eV}$ leads to a transient DNB anion with a very large excitation energy of $2.1 \mathrm{eV}$ plus the electron affinity of 1,3-DNB, $1.70 \mathrm{eV}$. For loss of NO from $\mathrm{DNB}^{-}$we assume a KER of $0.89 \mathrm{eV}$ which was measured for reaction 1, although at an electron energy of $0 \mathrm{eV}$. Loss of another NO lowers the total energy by another 0.68 $\mathrm{eV}$ (the KER of reaction 4 measured at $2.1 \mathrm{eV}$ ), and loss of $\mathrm{CO}$ lowers the energy by $1.32 \mathrm{eV}$ (the KER of reaction 7 measured at $2.1 \mathrm{eV}$ ). With these assumptions, the final product anion would be $0.1 \mathrm{eV}$ below the computed ground state, i.e., the excitation energy would be slightly negative. A negative value is physically impossible; the result may be due to uncertainties of the experimental and computational data. The excitation energy would become even more negative if one takes into account the vibrational excitation energy in the neutral fragments which is probably higher than thermal if complex rearrangement reactions are involved. However, the value of $0.89 \mathrm{eV}$ assumed for the kinetic energy released in the prompt formation of (DNB-NO) ${ }^{-}$was measured at an electron energy of $0 \mathrm{eV}$. It is possible that the KER would be lower at higher 
electron energy; after all the entries in Table II do not show any obvious correlation between the electron energy and the KER. By and large, the large KER values observed for reactions 4 and 7 in the $2.1 \mathrm{eV}$ resonance are not inconsistent with the computed reaction energies if one takes experimental and computational uncertainties into account.

\section{CONCLUSION}

In conclusion, we have presented a comprehensive study of metastable dissociation of anions that result from attachment of free electrons to all three isomers of dinitrobenzene. We have measured the energy dependence of the metastable ion yield, and the kinetic energy that is released in the metastable dissociation. Low-energy electrons trigger strongly exothermic metastable reactions that are highly isomer-specific. For some metastable reactions, resonances correlate with resonances in the yield of prompt, stable parent and fragment ions which suggests that these ions are the result of fast metastable reactions in the ion source. Surprisingly, the largest kinetic energy $(1.32 \mathrm{eV})$ is observed for the second step of a sequential metastable reaction, namely, NO loss from (1,3-DNB-NO)- followed by CO loss. Large kinetic energy releases are associated with reverse activation barriers, indicating complex rearrangement reactions. Energies computed for the various reaction channels are consistent with the experimental data, but calculations of transition states will be needed for a detailed understanding of the isomerization reactions.

\section{ACKNOWLEDGMENTS}

A.M. gratefully acknowledges a short term scientific mission to Queen's University Belfast granted by ESF EIPAM (ref. no. 1562) and a FWF Erwin-Schrödinger-abroad fellowship (J 2973-N20). S.D. gratefully acknowledges an APART scholarship from the Austrian Academy of Sciences. This work was supported in part by the Austrian Science Fund, Wien (FWF, projects P19073, L633, and I200 N29), the European Commission, Brussels (ITS-LEIF), the European Commission, Brussels, and the Austrian Ministry of Science (infrastructure grant to the LFU scientific computing platform).

${ }^{1}$ C. Mullen, A. Irwin, B. V. Pond, D. L. Huestis, M. J. Coggiola, and H. Oser, Anal. Chem. 78, 3807 (2006); B. V. Pond, C. Mullen, I. Suarez, J. Kessler,
K. Briggs, S. E. Young, M. J. Coggiola, D. R. Crosley, and H. Oser, Appl. Phys. B 86, 735 (2007).

${ }^{2}$ J. H. Bowie, Environ. Health Perspect. 36, 89 (1980).

${ }^{3}$ S. F. Nelsen, M. N. Weaver, A. E. Konradsson, J. P. Telo, and T. Clark, J. Am. Chem. Soc. 126, 15431 (2004); S. F. Nelsen, M. N. Weaver, and J. P. Telo, J. Am. Chem. Soc. 129, 7036 (2007); W. Danikiewicz, T. Bienkowski, D. Kozlowska, and M. Zimnicka, J. Am. Soc. Mass Spectrom. 18, 1351 (2007); J. P. Telo, S. F. Nelsen, and Y. Zhao, J. Phys. Chem. A 113, 7730 (2009).

${ }^{4}$ M. N. Mikhailov, A. S. Mendkovich, M. B. Kuminsky, and A. I. Rusakov, J. Mol. Struct.: THEOCHEM 847, 103 (2007).

${ }^{5}$ S. Chowdhury, E. P. Grimsrud, T. Heinis, and P. Kebarle, J. Am. Chem. Soc. 108, 3630 (1986).

${ }^{6}$ S. Chowdhury, T. Heinis, E. P. Grimsrud, and P. Kebarle, J. Phys. Chem. 90, 2747 (1986).

${ }^{7}$ E. K. Fukuda and R. T. McIver, J. Am. Chem. Soc. 107, 2291 (1985).

${ }^{8}$ R. S. Mock and E. P. Grimsrud, J. Am. Chem. Soc. 111, 2861 (1989).

${ }^{9}$ F. Zappa, M. Beikircher, A. Mauracher, S. Denifl, M. Probst, N. Injan, J. Limtrakul, A. Bacher, O. Echt, T. D. Märk, P. Scheier, T. A. Field, and K. Graupner, ChemPhysChem 9, 607 (2008).

${ }^{10}$ J. H. Bowie, T. Blumenthal, and P. Y. White, Aust. J. Chem. 31, 573 (1978)

${ }^{11}$ P. Sulzer, A. Mauracher, S. Denifl, M. Probst, T. D. Märk, P. Scheier, and E. Illenberger, Int. J. Mass Spectrom. 266, 138 (2007).

${ }^{12}$ L. A. Curtiss, P. C. Redfern, and K. Raghavachari, J. Chem. Phys. 127, 124105 (2007).

${ }^{13}$ W. C. Wiley and I. H. McLaren, Rev. Sci. Instrum. 26, 1150 (1955); J. H. D. Eland, Meas. Sci. Technol. 4, 1522 (1993); T. A. Field, A. E. Slattery, D. J. Adams, and D. D. Morrison, J. Phys. B 38, 255 (2005).

${ }^{14}$ D. Huber, M. Beikircher, S. Denifl, F. Zappa, S. Matejcik, A. Bacher, V. Grill, T. D. Märk, and P. Scheier, J. Chem. Phys. 125, 84304 (2006).

${ }^{15}$ R. G. Cooks, J. H. Beynon, R. M. Caprioli, and G. R. Lester, Metastable Ions (Elsevier, Amsterdam, 1973).

${ }^{16}$ S. Feil, O. Echt, K. Gluch, V. G. Hasan, S. Matt-Leubner, T. Tepnual, V. Grill, A. Bacher, P. Scheier, and T. D. Märk, Chem. Phys. Lett. 411, 366 (2005).

${ }^{17}$ M. F. Jarrold, J. Illies, N. J. Kirchner, W. Wagner-Redeker, M. T. Bowers, M. L. Mandich, and J. L. Beauchamp, J. Phys. Chem. 87, 2213 (1983).

${ }^{18}$ S. Matt, O. Echt, R. David, A. Stamatovic, and T. D. Märk, J. Chem. Phys. 113, 616 (2000).

${ }^{19}$ In principle, the ion signal at $168 \mathrm{u}$ will include contributions from (DNB$\mathrm{H})^{-}$ions that contain one ${ }^{13} \mathrm{C}$ atom (natural abundance $1.1 \%$ ). In practice, however, any such contamination is negligible because the $167 \mathrm{u}$ signal is orders of magnitude weaker than the $168 \mathrm{u}$ signal; in a previous publication the $167 \mathrm{u}$ ion signal was not even identified for the 1,2-DNB and 1,4-DNB isomers. ${ }^{11}$

${ }^{20}$ S. Matt-Leubner, A. Stamatovic, R. Parajuli, P. Scheier, T. D. Märk, O. Echt, and C. Lifshitz, Int. J. Mass Spectrom. 222, 213 (2003).

${ }^{21}$ M. J. Frisch, G. W. Trucks, H. B. Schlegel et al., GAUSSIAN 03, Gaussian, Inc., Wallingford, CT, 2004; M. J. Frisch, G. W. Trucks, H. B. Schlegel et al., GAUSSIAN 09, Gaussian, Inc., Wallingford, CT, 2009.

${ }^{22}$ T. H. Dunning, J. Chem. Phys. 90, 1007 (1989).

${ }^{23}$ J. Marks, P. B. Comita, and J. I. Brauman, J. Am. Chem. Soc. 107, 3718 (1985).

${ }^{24}$ J. Schiedt and R. Weinkauf, J. Chem. Phys. 110, 304 (1999). 